\title{
Transmissão e memória
}

\author{
William Marx
}

Tradução de Dirceu Magri

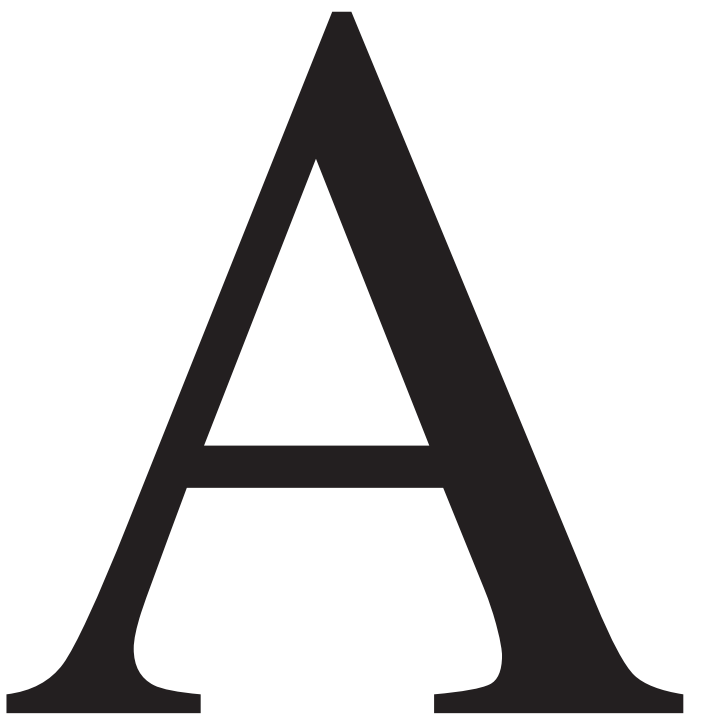

UMA NOVA RELAÇÃO COM 0 TEMPO

criação do conceito moderno de literatura, na virada dos séculos XVIII e XIX, foi acompanhada por uma transformação radical da relação com o tempo. As antigas belas-letras foram baseadas na perpetuação, se não real, ao menos difundida e, em todo caso, objeto de uma ampla crença, de um modelo clássico diretamente herdado da Antiguidade, cuja preeminência era apenas parcialmente contestada. O que, com o Romantismo, é agora chamado de literatura, funciona de uma forma diferente: a relação com a tradição desaparece

WILLIAM MARX é escritor, ensaísta, crítico, historiador da literatura e professor do Collège de France. É autor de, entre outros, Vie du lettré (Les Éditions de Minuit). 
em proveito de uma afirmação do indivíduo. A obra torna-se a expressão da genialidade.

No entanto, isso não significa que cada obra seja agora considerada isoladamente, como um hápax, que por natureza escaparia a toda comparação. Pelo contrário, o gênio, em si, existe e é medido apenas em relação à massa de seus contemporâneos e dos homens que o precederam e dos quais ele se distingue. Em outras palavras, a estética mais individualista que começa então a prevalecer revela necessariamente novos contrastes entre as obras literárias, contrastes que se manifestam quer em sincronia, quer na diacronia. Não que esses contrastes e diferenças não existissem antes, no tempo das belas-letras; mas não se prestava atenção a eles; a crítica só podia avaliar a maior ou menor distância de tal obra ou de tal período em relação aos modelos antigos; os relevos foram esmagados, a paisagem, nivelada.

Com a criação da ideia moderna da literatura, é a história da literatura que finalmente se torna possível. Enquanto as belas-letras operavam em um modo paradigmático, constantemente reescrevendo o mesmo texto em uma espécie de palimpsesto infinito das obras clássicas, a literatura recém-nascida escolheu o modo sintagmático: em vez de reescrever no mesmo rolo, ela o desenrola, associando-o a outros subsequentes. $\mathrm{O}$ nascimento da literatura é inseparável da ideia de que essa literatura tem uma história que se desenvolve e participa do progresso do espírito humano.

Ora, é essa crença que, de certa forma, entra em colapso na virada dos séculos XIX e XX. O Simbolismo, de fato, havia representado o desenvolvimento mais completo do ideal romântico da literatura: nele, a linguagem poética operava uma cisão radical com a língua comum, a obra permitia penetrar os segredos mais íntimos do Universo, o criador se exilava da sociedade, de modo que ao levar o projeto romântico ao seu mais alto nível, ao realizá-lo, o Simbolismo pôs fim ao processo que havia sido engendrado um século antes.

Poucos, como Valéry, expressaram tão bem essa consciência de conclusão de um ciclo. Sua ideia é a seguinte: com o Simbolismo, a evolução literária no final do século XIX leva logicamente, e pela primeira vez, a um destaque da natureza própria da poesia. Ele escreveu em 1920: "No final do século XIX, finalmente vimos um desejo notável em nossa literatura de isolar definitivamente a Poesia de qualquer outra essência que não seja ela mesma" (Valéry, 1957a). E mais: "Nós tocávamos pelo nosso desejo a própria essência de nossa arte, [...] nós havíamos realmente decifrado a significação geral do trabalho de nossos antepassados [...] (Valéry, 1957a, p. 1.275). A poesia simbolista tinha sido capaz de manifestar a própria essência de toda a poesia, até então misturada às escórias que nela dissimulavam seu verdadeiro princípio. Assim, Valéry propõe nada mais nada menos do que uma leitura estritamente hegeliana da história literária: com o Simbolismo, o absoluto está incorporado na história. A história - a história da literatura, entenda-se - está finalmente ultrapassada.

Mas o fim da história da literatura tem duas consequências. Em primeiro lugar, torna possível, em uma superação suprema, a consciência dessa mesma história: agora que foram vividos, o processo histórico e a realidade resultante desse processo podem ser pensados; um novo discurso crítico é capaz de emergir e ir além da abordagem individual das obras e autores para propor uma visão geral do desenvolvimento da literatura. 
Ferdinand Brunetière (1892) já havia considerado descrever "a evolução dos gêneros na história da literatura" - sem realizar a contento o empreendimento. Valéry levará o projeto a seu termo, apresentando a poesia simbolista como o gênero eminentemente mais literário (poesia) no interior do movimento essencialmente mais literário que jamais existiu (Simbolismo). Ele se permite, como último poeta simbolista, quer dizer, como poeta - até mesmo como escritor por excelência, falar de toda a literatura na medida em que, através da poesia simbolista, toca-se na essência até mesmo da literatura. A postura teórica e generalizante do crítico Valéry decorre naturalmente de uma situação histórica particular, a do Valéry poeta. A suposição do Simbolismo na "poesia pura" (Valéry, 1957a, p. 1.270) se desdobra em uma transfiguração do crítico que, de humilde servo e comentador de obras, se transforma em teórico da literatura. A defesa valeriana do Simbolismo estabelece, assim, as bases para uma nova abordagem crítica: aquelas de uma literatura geral. O fim da literatura coincide necessariamente com o nascimento da única crítica verdadeira. No Collège de France, Valéry deseja então o advento de uma história da literatura livre de incidentes biográficos e anedotas, uma história que "pudesse até mesmo se fazer sem que o nome de um escritor fosse nela pronunciado" (Valéry, 1957b, p. 1.439).

Mas o que torna possível um discurso específico sobre a essência da literatura torna também mais incerta, ipso facto, a sua própria existência. "De acordo com o princípio de que é apenas na casa em chamas que o problema arquitetônico das fundações se torna visível pela primeira vez", escreve Giorgio Agamben (1970, p. 176), assim a arte "levada ao extremo da sua vocação, torna visível seu projeto de origem”. É o mesmo Valéry que se permite definir as propriedades essenciais da obra literária e que, algumas décadas antes, havia decidido se emparedar em um silêncio poético quase completo, do qual quase nunca saíra. De forma mais geral, o fim do Simbolismo determinou de modo concreto os limites do projeto literário cujos contornos haviam sido fixados com o Romantismo; com o apagamento do Simbolismo, é a própria literatura que desaparece vagamente do horizonte. Aqui, alguma coisa se acaba. É realmente possível, nessas condições, continuar no mesmo caminho e prosseguir como se nada tivesse já sido totalmente explorado?

\section{VANGUARDAS E RETAGUARDAS EM LUTA CONTRA A HISTÓRIA}

O sentimento de fim da história obriga a reversões dramáticas: é toda a relação da literatura com o tempo que foi alterada no início do século XX, e o século que se abriu foi então totalmente marcado por esse trauma profundo. Grosso modo, duas posições radicais entraram em conflito. Duas, porque, chegando-se a um beco sem saída, não há outra alternativa a não ser recuar ou pular. As retaguardas fizeram a primeira escolha: se o Simbolismo fora um fracasso, era necessário retornar e voltar ao ponto precedente, à bifurcação fatal, aquela que precisamente havia levado ao Simbolismo. No entanto, antes da bifurcação romântica, havia apenas Classicismo, na oposição ao qual o Romantismo tinha originalmente considerado. A nova corrente será, portanto, e inevitavelmente, neoclássica. Pierre Lasserre 
agravou a situação em 1907, com sua tese de doutorado sobre o Romantismo francês, na qual ele resumiu todas as queixas acumuladas anteriormente contra esse movimento, em particular por Charles Maurras. Em seguida, o protesto foi rapidamente transmitido por várias revistas: Les Marges, de Eugène Montfort, Le Divan, de Henri Martineau, e especialmente a Revue Critique des Idées et des Livres, criada em 1908, assim como Les Waspes, fundada em 1909, notadamente por Jean-Marc Bernard e Raoul Monier.

Esse movimento de "Renascimento clássico", como às vezes gosta de ser chamado, não é uma escola unificada, com mestres e doutrina determinados. Na realidade, como a multiplicidade das revistas que tratam do assunto deixa claro, trata-se mais de uma nebulosa em que a controvérsia interna muitas vezes toma conta da ação comum. Caso típico desse gosto de controvérsia: Les Disciplines, uma das raras sínteses doutrinárias das ambições do Renascimento clássico, na qual Henri Clouard, da Revue Critique, acerta suas contas com os "tradicionalistas" agrupados em torno de Adrien Mithouard e sua revista L'Occident, a quem ele fustiga por sua timidez política, embora, de maneira a priori mais eficaz, Clouard (1913, pp. 65-82) poderia tê-los tomado como aliados.

No entanto, as palavras de ordem gerais do movimento podem ser resumidas facilmente: promoção de uma literatura nacional e provincial; retorno à tradição clássica do século XVII, às formas poéticas regulares, à clareza; antissimbolismo de princípio. Embora seja verdade que, como movimento, o Renascimento clássico desapareceria mais ou menos nos tumultos da Primeira Guerra Mundial, encontramos, contudo, seus ecos durante grande parte do século, de Charles
Péguy a Albert Camus, de Jacques Rivière a Jean Paulhan, passando por Paul Valéry, Jean Cocteau ou Jean Giraudoux.

No entanto, não é coincidência se, no exato momento em que aparece o Renascimento clássico, surge o movimento antagônico, que opta por pular o obstáculo em vez de recuar: a vanguarda é a outra solução, exatamente simétrica, para o problema apresentado pelo fim da história da literatura. O "Manifesto Futurista”, como aparece no Le Figaro de 20 de fevereiro de 1909, define claramente os desafios do debate. Por um lado, o impasse histórico é total - neste ponto, as retaguardas concordariam: "Estamos no promontório de séculos!... De que serve olhar para trás, desde que tenhamos que quebrar os misteriosos derramamentos do Impossível? O Tempo e o Espaço morreram ontem" (Marinetti, 1979, pp. 152-3). Por outro lado - e é aqui que aparece a principal diferença com as retaguardas -, qualquer retrocesso é impossível; o passado nunca pode ser usado como refúgio: "Queremos demolir os museus, as bibliotecas [...]. Queremos libertar a Itália de sua gangrena de professores, arqueólogos, cicerones e antiquários" (Marinetti, 1979, p. 153). Marinetti não publica seu manifesto em Paris por acaso: se a literatura nascida com o Romantismo alcançou sua maior realização na França, é da França que a solução deve vir.

As vanguardas que sucederão o Futurismo - Dada, o Surrealismo - não divergirão fundamentalmente sobre as soluções a serem trazidas: todos dão primazia à "praxis vitale" (Lebenspraxis) em relação à esfera artística, fazendo uso da expressão de Peter Boerger (1974, p. 67), a fim de reverter completamente a escala de valores estabelecida pelo Romantismo, segundo a qual a ordem de espírito e 
criação deve ditar sua lei às forças da vida e à materialidade da existência. $\mathrm{O}$ rompimento invocado é brutal. Não é indiferente, desse ponto de vista, que o Surrealismo tenha se imposto ao promover como figura de referência o saltar de um assunto para outro ${ }^{1}$ ou a incongruência, que constituem a própria estrutura da história como desejado e provocado pelos movimentos de vanguarda, ou seja, uma história que, avançando por rupturas, preservaria bem pouco os pontos em comum entre o instante $t$ e o instante $t+I$ como entre uma máquina de costura e um guarda-chuva sobre uma mesa de dissecação: deve-se "quebrar o encadeamento insignificante dos fatos" (Pierre \& Losfeld, 1980, p. 55). Por si só, o elogio surrealista do acaso e da não premeditação implica a abolição de toda história literária concebida como uma cadeia sintagmática coerente.

Assim, apesar das aparências, vanguardas e retaguardas continuam a mesma luta contra o curso normal da história da literatura, supostamente terminada em fracasso, e propõem orientar essa história para direções inesperadas.

\section{A LITERATURA DO SÉCULO XX: ENTRE RESULTADO E SUPERAÇÃO}

É por isso que a relação com o passado nunca foi vivida com mais angústia do que na literatura do século XX, em que o problema da memória e da transmissão surge em termos particularmente difíceis, e não sem

1 No original, "le coq-à-lâne", expressão que em algumas regiões do Brasil poderia ser traduzida por "mudar de pato para ganso", quando se quer dizer que uma pessoa saltou de um assunto para outro sem alguma coerência (N. do T.). perigo. De fato, a obra literária que segue o suposto fim da literatura deve mostrar que levou esse fim em conta. De uma forma ou de outra, deve claramente propor-se tanto como resultado quanto como a superação de toda a história da literatura. O resultado, porque ela não pode deixar de se escrever, enquanto obra literária, no mecanismo evolutivo da literatura iniciado a partir do período romântico. A superação, porque ela não deve nem ao menos declarar a recusa dessa história a partir de agora encerrada. Resultado e superação são, portanto, antinômicos e criam uma tensão que é fonte de ansiedade, não menos do que a energia criativa. A resolução aparente dessa tensão requer uma manobra estética: na prática, as obras tendem a acentuar uma dessas duas funções, resultado ou superação, e a colocar a outra em espera. Mas o desequilíbrio espreita...

É assim que retaguardas e vanguardas assumem ostensivamente o partido da superação, as primeiras promovendo a estética que antecede o próprio aparecimento da literatura; as últimas, demolindo a ordem literária estabelecida e tentando inventar um futuro radicalmente imprevisível. Ambas, em suma, negam a história de onde vieram. É nisso precisamente que elas são características de uma literatura do século XX, que, tendo perdido todas as suas relações temporais, é forçada a criar outras, artificiais, para remediar essa perda. Isso é claro o suficiente para as retaguardas, que perturbam o curso normal da história. Mas não é menos para a vanguarda, pois a invenção da tensão vanguardista, tensão tão política quanto estética, não teve outra função que não impor uma orientação poderosa, mas em parte fictícia, sobre uma história cujo sentido parecia ruir. A vanguarda força a 
passagem para o futuro: busca sair da crise pela frente ou, simplesmente, sair da história. Vincent Kaufmann (1997, p. 11) diz isso à sua maneira: os autores de vanguarda "jamais mediram-se em relação a algo que não seja um projeto de livro total: o Livro enquanto representante do fim do livro, em todos os sentidos da palavra".

As estéticas da superação, sejam elas da retaguarda, sejam da vanguarda, são muito mais radicais do que as do resultado. Elas também são muito mais fáceis de apreender e de uma coerência muito mais óbvia, mesmo que a radicalidade delas inevitavelmente as separe de grande parte do público e tenda a colocá-las à margem do campo literário.

\section{A RELAÇÃO AMBÍGUA COM $O$ SIMBOLISMO}

As estéticas do resultado, por outro lado, se também querem marcar um esforço de superação, encontram um equilíbrio mais instável. Essa instabilidade se manifesta em particular, no início do século $\mathrm{XX}$, no que diz respeito à memória do Simbolismo. A relação com esse movimento é uma das questões mais fortes em torno da qual circunda a vida literária. O problema surge nesses termos: reivindicar o legado do Simbolismo o impede de propor a sua superação? A instabilidade é gritante no caso de Jean Moréas: de fato, coube ao autor do primeiro manifesto do Simbolismo virar a casaca e aparecer alguns anos depois, graças à fundação da Escola Romana, como a principal inspiração do Neoclassicismo. Essa palinódia tão rápida, entre 1886 e 1891, é uma boa ilustração das rupturas atravessadas pelo próprio conceito de literatura.
A história se reproduziu quase 20 anos depois de uma forma muito mais dramática: duas opiniões divergentes, não mais no mesmo homem com alguns anos de intervalo, mas na mesma revista, ao mesmo tempo. Trata-se da famosa anedota do falso começo da Nouvelle Revue Française. Na primeira edição de novembro de 1908, Léon Bocquet propunha um relato bastante positivo de um ataque de Jean-Marc Bernard a Mallarmé, publicado na La Société Nouvelle alguns meses antes: "um trabalho de demolição" realizado, segundo Bocquet (1908, p. 78), "com grande reserva e habilidade".

O próprio Bernard era um defensor do Neoclassicismo - ao lado, portanto, das retaguardas. Para ele, estava claro que "parnasianos e simbolistas são meramente a cauda do Romantismo e não têm feito mais que exagerar e, consequentemente, distorcer os processos existentes" (Bernard, 1908, p. 191): com o Simbolismo, não é apenas todo o século XIX que é rejeitado, mas sobretudo a ideia moderna de literatura. Ao definir, contra Albert Mockel, a arte de Mallarmé como a antítese do "Classicismo", Bernard (1908, p. 192), contudo, agiu firmemente, concluindo assim seu artigo:

"Que Mallarmé, de agora em diante, viva na mente, no coração e nas obras dos discípulos amados, aceito-o, e tanto melhor para ele! Que esteja destinado a se tornar um novo parteiro de espíritos, é muito possível. Mas não esqueçamos, porém, que Sócrates, com muita cautela, nunca escreveu nada. Ele se contentava em ser um encantador do verbo e da inteligência. Infelizmente para Stéphane Mallarmé, ainda possuímos suas Poesias e suas Divagações" (Bernard, 1908, p. 195). 
Ao atingir tanto Mallarmé quanto o fato de que ele tinha discípulos (o adversário declarado era Jean Royère), o artigo questionava a própria posteridade do Simbolismo e seu lugar na história. Ele tomava deliberadamente o lado da superação em vez do resultado.

A revisão favorável proposta por Bocquet desagradou tanto a André Gide quanto a Jean Schlumberger, que romperam com o outro clã fundador da Nouvelle Revue Française, formado por Eugène Montfort e seus amigos (Anglès, 1978, p. 120). A NRF só renasceria - de fato - em fevereiro de 1909, com uma nova primeira edição, que de alguma forma anulava a precedente. No entanto, a comparação dos editoriais das duas primeiras edições é bastante instrutiva. O texto introdutório não assinado, de novembro de 1908, ressaltou, com grande insistência, o fim do movimento simbolista:

"Os escritores que compõem hoje a Nouvelle Revue Française pertencem à geração que, na cronologia literária, seguiu imediatamente o Simbolismo. [...] Ao reunir as energias anteriormente dispersas de romancistas e poetas que começaram há dez ou doze anos, é a esperança dos fundadores desta revista que eles ajudem a emergir mais cedo, tanto aos seus próprios olhos quanto aos olhos dos críticos, a nova contribuição que deve distinguir os escritores de hoje dos de ontem.

Se esta revista, como podemos ver, não é exatamente uma 'revista de jovens', é, no entanto, uma revista jovem de agora em diante aberta à geração em ascensão" (NRF, 1908, p. 1).

Tratava-se claramente, portanto, de distinguir-se da geração simbolista. Embora nenhum julgamento explícito, positivo ou negativo, tenha sido feito sobre Simbolismo, situavam-se mais do lado da superação. $\mathrm{Na}$ edição de fevereiro de 1909, Schlumberger estaria visivelmente trabalhando para reequilibrar o peso respectivo da superação e do resultado, afirmando primeiro a infalível relação "filial" unindo a revista e os mestres mais recentes (o nome de Mallarmé não é mencionado, mas trata-se obviamente dele):

“[...] é apenas no que diz respeito a obras significativas - e na maioria das vezes daquelas do passado - que as amizades são intransigentes. As preferências permanecem livres, mas não a qualidade da admiração, nem um certo sentimento, por assim dizer, de dependência filial"' (Schlumberger, 1909, p. 6).

Acima de tudo, Schlumberger se distanciava da retaguarda neoclássica, descrita como uma "reação retrógrada":

"Se quisermos nos alegrar em uma dinâmica cada vez maior em direção aos nossos séculos XVII e XVIII, só depois de reservas terem sido feitas. Esse movimento é, para muitas pessoas, uma marca de vertigem e pavor. Que alguns reneguem sistematicamente toda nossa literatura romântica, ou que os outros, por ignorância, negligenciem tudo o que o final do século XIX nos deixou de forte e requintado; em todos é a ansiedade de se sentir perdidos, separados por um abismo vazio, das glórias seguras da cultura francesa" (Schlumberger, 1909, p. 10).

Em suma, para a Nouvelle Revue Française de 1909, a superação não deve triunfar sobre o resultado: é preciso aceitar o legado do Romantismo e do Simbolismo para pretender superá-lo. A "ansiedade" característica das estéticas da pura superação está condenada. 
Assim, entre as duas primeiras edições da $N R F$, a relação com o Simbolismo é quase invertida: não se poderia encontrar sinal mais forte da instabilidade da memória literária no início do século $\mathrm{XX}$, nem da relação ambivalente que a literatura deste século tem com sua história. Sem dúvida, os dois editoriais contraditórios foram assinados por duas mãos diferentes. No entanto, a questão da relação com Mallarmé e, de modo mais geral, do Simbolismo, tinha sido deixada suficientemente vaga nas conversas entre o clã gidiano e o de Montfort, durante a fundação da $N R F$, para que tais textos abertamente anti-simbolistas pudessem ser incluídos na edição de novembro de 1908 sem nenhum escrúpulo particular por parte de seus autores.

No final, quando a revista teve um novo começo em 1909, a questão foi resolvida: o classicismo complexo e ambíguo defendido pela $N R F$ veria no Simbolismo uma experiência útil que valia a pena ser tentada e que tinha que ser aprendida. Esta será a posição de Albert Thibaudet ou Paul Valéry. Por outro lado, o ultraclassicismo defendido pelos neoclássicos, e que conhecerá sua era de ouro entre os anos de 1908 e 1914, será baseado em uma única observação: o fracasso do Simbolismo. Mas, que o Simbolismo tenha fracassado, para alguns, ou tenha deixado um legado válido, para outros, isso não impede a $N R F$ e os neoclássicos de comungarem uma única exigência: ir além do momento simbolista e aproveitar a oportunidade histórica, a junctura rerum ${ }^{2}$, para propor outra forma de fazer literatura, uma literatura que,

2 Charles Maurras (1905, p. 285) fala do "junctura rerum, a articulação onde a ossatura se dobra, e que em todos os outros lugares é rígida, o lugar onde a mola da ação vai tocar". para a $N R F$, assim como entre os neoclássicos, assinala uma certa reforma intelectual combinada com restrição formal e que, em ambos os casos, é um claro afastamento de muitas das aspirações do Simbolismo.

\section{A INVENÇÃO DAS TRADIÇÕES}

Para gerenciar a dupla restrição antitética de resultado e superação, a literatura do século $\mathrm{XX}$ teve que inventar referências originais, que a ancorassem em um passado e uma história, dando-lhe distância suficiente de seus antecessores mais imediatos. Em 1920, Camille Mauclair (1920, p. 109) constata que a tradição havia se tornado a palavra mestra. Cada um tinha a sua própria. Para os defensores do renascimento clássico, adeptos de um neoclassicismo reacionário puro e duro, tratava-se do Classicismo do século XVII, que tinha que ressuscitar tal como era. Mas, de modo menos esperado, as vanguardas também poderiam reivindicar sua própria tradição - uma tradição estritamente complementar, como deveria ser, a das retaguardas: na famosa lista de precursores do Surrealismo proposta pelo primeiro Manifesto, saltamos diretamente de Dante e Shakespeare para Young, Swift, Sade e Chateaubriand, de modo que nenhum escritor clássico do século XVII francês tenha sido citado; por outro lado, o Romantismo e, de modo mais geral, a poesia do século XIX são amplamente representados (Breton, 1988, pp. 328-9). A lição é clara: o Surrealismo homenageia aqueles que são proscritos pelo Neoclassicismo, e vice-versa. Mas, em ambos os casos, a tradição serve apenas para demolir a história, uma vez que alguns os defensores do renascimento clássico - a 
utilizam para negar o processo histórico de onde vêm, enquanto os outros - os surrealistas - promovem uma visão errática e absurda da mesma história.

Mais complexa é a tarefa daqueles que reivindicam uma estética do resultado: devem reivindicar a herança, toda a sua herança, mas propondo uma nova concepção da literatura. É isto o que tem sido chamado de "Classicismo moderno"3 e que Jacques Rivière, na primeira edição da Nouvelle Revue Française após a guerra, assim define:

"Diremos tudo o que nos parece apontar para um renascimento clássico, não textual e de pura imitação, como os seguidores de Moréas e os escritores da Revue Critique o entenderam e o definiram antes da guerra, mas profundo e interior" (Rivière, 1919).

Albert Thibaudet (1913, p. 374) foi ainda mais longe ao denunciar a miragem neoclássica: "Acredito que se pode estabelecer este princípio, de que uma literatura clássica não pode nascer de uma outra na mesma língua". Por outro lado, ele poderia conceber perfeitamente a hipótese de "um classicismo estrangeiro inspirado no classicismo francês" (p. 377). A recíproca é verdadeira: poder-se-ia também imaginar um novo Classicismo francês inspirado em clássicos estrangeiros. Foi o que aconteceu: Shakespeare, Goethe e Dostoiévski foram homenageados por todos os clássicos modernos do século $\mathrm{XX}$, que foram capazes de redefinir uma tradição ao mesmo tempo prestigiosa e original, e de

3 A expressão é de Henri Ghéon, pronunciada na L'Ermitage, em 1904, e citada por Décaudin (1981, p. 331). propor uma solução elegante para equilibrar o resultado e a superação.

\section{REFERÊNCIA A POE}

Edgar Allan Poe foi um dos autores mais frequentemente convocados neste contexto. Assim, os anos 20 na França aparecem retrospectivamente como os "anos Poe" por excelência. Para citar apenas alguns exemplos, em 1925, Paul Souday (1925, p. 11) relatava sua influência sobre escritores franceses em um artigo no New York Times Book Review; René Lalou retraduziu em 1926 seus três manifestos fundamentais: "O princípio poético", "A filosofia da composição" e "A essência do verso" (Poe, 1926); e nada menos que três teses sobre a recepção de Poe na França se sucederam e se repetiram sem escrúpulo, ao ritmo de uma a cada quatro ou cinco anos: Louis Seylaz em 1923, Célestin Pierre Cambiaire em 1927, Léon Lemonnier em 1932 .

Essa moda às vezes ia ao ponto do absurdo: a influência de Poe podia ser encontrada em todos os lugares, mesmo nas ideias mais comuns. A respeito de um julgamento muito banal de André Thérive, segundo o qual é importante distinguir entre a linguagem da prosa e a linguagem da poesia, Seylaz (1923, p. 178) proclama: “Aqui novamente reconhecemos o poderoso pensamento do poeta americano, que é confundido com o próprio sopro da arte". Na verdade, além do entusiasmo natural de qualquer doutorando por seu tema de pesquisa, acima de tudo é preciso reconhecer na frase de Seylaz o índice do estilo de uma época, que atribui

\footnotetext{
4 Verificar dados nas Referências.
} 
a Poe a autoria de todos os lugares-comuns da crítica literária. O Poe dos anos 20 às vezes não é nada mais do que o mestre de filosofia do sr. Jordan, ensinando a seu aluno que ele fala em prosa.

De fato, essa súbita preeminência de Poe permitia dar coerência a um período bastante complexo da história da literatura: o do final do século XIX. Em vez de uma pluralidade desordenada de movimentos justapostos uns aos outros, a referência comum a Poe trazia à tona a lógica de um desenvolvimento contínuo, de Baudelaire a Mallarmé.

Esta é a força dos números: assim como, na linguística comparada, pode-se concluir que um parentesco entre duas línguas só pode ser demonstrado a partir de três lexemas comuns, da mesma forma a história literária admite apenas a existência de movimentos que reúnam pelo menos três escritores. Ao completar o trio, a adjunção do termo Poe como ponto de partida conferia assim a força de uma tradição nova àquilo que para alguns parecia ser uma forma de decadência e ruptura patológica da literatura. Poe não apenas explicou a aparição de Baudelaire e Mallarmé: ele justificou sua existência.

$\mathrm{Se}$, graças a essa fantasia da genealogia americana, o Simbolismo podia dar a ilusão de escapar da pesada herança do Romantismo francês e europeu, tornava-se ao mesmo tempo muito mais fácil reapropriar-se da memória poética do final do século XIX. Atribuiu-se então a Poe a paternidade de toda uma tradição, e essa tradição desempenhou um papel fundamental na formação do cânone: foi assim que ele foi utilizado, especialmente por Valéry. Já em 1921, no momento em que começou a ser reconhecido, sem perder tempo, ele prefaciou Eureka (Valéry, 1957c, pp. 854-67). Em 1922, ele deu uma conferência sobre "As ideias de Edgar Poe" (Lawler, 1989, pp. 87-132), que René Lalou imediatamente relatou em sua História da literatura francesa contemporânea, nos seguintes termos:

"Paul Valéry deu novamente outra palestra aos Amigos dos Livros (junho de 1922), 'puro trabalho relâmpago' sobre as ideias de Edgar Poe - este Edgar Poe, meio real, meio inventado por Baudelaire e Mallarmé, que permanece, apesar de tanto esforço, 'um pouco menos sólido do que Edmond Teste"” (Lalou, 1922, p. 506).

Se Lalou manifesta um ceticismo tão forte a respeito da figura de Poe, como apresentado por Valéry, e a coloca no mesmo nível de uma criatura de ficção, é porque ele claramente discernia a função essencial que o escritor americano cumpria na estratégia literária do poeta francês: tratava-se de dar à sua própria poesia a espessura de uma tradição tanto supranacional quanto enraizada na história da literatura. O Edgar Poe de Valéry, como o de Baudelaire e o de Mallarmé, é um pouco como o Lautréamont ou o Aloysius Bertrand dos surrealistas: o chefe tutelar e mítico necessário para toda vanguarda.

A insistência na linhagem Poe-Baudelaire-Mallarmé permitiu que Valéry escapasse do debate estéril que opunha o Classicismo e o Romantismo, valorizando uma terceira via com frequência desacreditada: o Simbolismo. Enquanto o Classicismo e o Romantismo se engendravam mutuamente através de sucessivas rebeliões, o Simbolismo reivindicava, em vez disso, uma origem totalmente externa, vinda do outro lado do Atlântico. "Ninguém é um profeta em seu país"; "pode 
mentir quem vem de longe": a sabedoria das nações permite compreender com bastante clareza como Poe permitiu deixar para trás de si uma polêmica antirromântica com implicações políticas arriscadas, alegando ser de uma autoridade percebida como neutra.

Não somente Poe, teórico romântico do Classicismo, transcendia admiravelmente a antítese dos dois termos, mas também transmitia esta propriedade para seu discípulo francês, Baudelaire, sobre o qual Valéry (1957d, p. 604) escrevia em 1924 que, "embora romântico de origem, e até mesmo romântico por seus gostos, [ele] pode às vezes ser um clássico". O debate anti- -romântico finalmente acabou. Como seus mestres, graças ao prestígio de um poeta americano traduzido precocemente por um francês, Valéry podia se fazer tudo para todos, clássico para os classicistas, vanguarda para os vanguardistas.

\section{$* * *$}

No século XX, as tradições se inventam apenas com o pretexto de recriar ou refundar a própria literatura: os distúrbios da memória literária coincidem com uma ruptura dos modelos, ou mesmo uma mudança de paradigma, e nisso pode-se decifrar os sintomas de um certo fim de história.

\section{REFERÊNCIAS}

AGAMBEN, Giorgio. L'uomo senza contenuto. Milano, Rizzoli, 1970.

ANGLÈS, Auguste. André Gide et le premier groupe de "La Nouvelle Revue française", t. I: La formation du groupe et les années d'apprentissage (1890-1910). Paris, Gallimard, 1978. BERNARD, Jean-Marc. "Stéphane Mallarmé et l'idée d'impuissance". La Société Nouvelle, $14^{\mathrm{e}}$ année, $2^{\mathrm{e}}$ série, $\mathrm{n}^{\circ} 2$, août 1908.

BOCQUET, Léon. “Les revues". La Nouvelle Revue Française, n 1, novembre 1908, p. 78. BRUNETIÈRE, Ferdinand. L'Évolution des genres dans l'histoire de la littérature. Paris, Hachette, 1892.

BÜRGER, Peter. Theorie der avantgarde. Frankfurt am Main, Suhrkamp, 1974.

CAMBIAIRE, Célestin Pierre. The influence of Edgar Allan Poe in France. New York, Stechert, 1927.

CLOUARD, Henri. Les disciplines: nécessité littéraire et sociale d'une renaissance classique. Paris, Rivière, 1913.

DÉCAUDIN, Michel. La crise des valeurs symbolistes: vingt ans de poésie française (18951914). Genève, Slatkine, 1981.

KAUFMANN, Vincent. Poétique des groupes littéraires (avant-gardes 1920-1970). Paris, PUF, 1997. 
LA NOUVELLE Revue Française, ${ }^{\circ}$ 1, novembre 1908, p. 1.

LALOU, René. Histoire de la littérature française contemporaine (1870 à nos jours). Paris, Crès, 1922.

LASSERRE, Pierre. Le romantisme français: essai sur la révolution dans les sentiments et dans les idées au XXe siècle. Paris, Mercure de France, 1907.

LAWLER, James. "Les idées d'Edgar Poe", in Edgar Poe et les poètes français. Paris, Julliard, 1989.

LEMONNIER, Léon. Edgar Poe et les poètes français. Paris, Éditions de la Nouvelle Revue Critique, 1932

MARINETTI, Filippo Tommaso. "Manifeste du futurisme" (1909), in Giovanni Lista (éd.). Le futurisme. Lausanne, L'Âge d'homme, 1979.

MAUCLAIR, Camille. "De Flaubert et du style". La Semaine Littéraire, n. 1.336, Genève, 6 mars 1920, p. 109.

MAURRAS, Charles. "Mademoiselle Monk ou la génération des événements", in L'Avenir de l'intelligence. Paris, Fonteming, 1905.

PIERRE, José; LOSFELD, Éric. "La révolution d'abord et toujours!". L'Humanité, 21 septembre 1925, repris dans José Pierre (éd.). Tracts surréalistes et déclarations collectives, t. I. Éric Losfeld/Le Terrain vague, 1980, p. 55.

POE, Edgar Allan. Trois manifestes. Traduction de René Lalou. Paris, Kra, 1926.

RIVIĖRE, Jacques. "La Nouvelle Revue Française". La Nouvelle Revue Française, juin 1919, repris dans Pierre Hebey (éd.). L'Esprit NRF (1908-1940). Paris, Gallimard, 1990, p. 243.

SCHLUMBERGER, Jean. "Considérations". La Nouvelle Revue Française, n. 1, février 1909, p. 6.

SEYLAZ, Louis. Edgar Poe et les premiers symbolistes français (1923). Genève, Slatkine Reprints, 1979.

SOUDAY, Paul. "Poe's Influence on French Writers". The New York Times Book Review, 22 February, 1925, p. 11.

THIBAUDET, Albert. "L'Esthétique des trois traditions". La Nouvelle Revue Française, vol. IX, n' 51, mars 1913, p. 374.

VALÉRY, Paul. "Avant-propos à connaissance de la déesse" (1920), in J. Hytier (éd.). Variété; oeuvres. Paris, Gallimard (coll. Bibliothèque de la Pléiade, t. I), 1957a.

VALÉRY, Paul. "L'Enseignement de la poétique au Collège de France" (1937), in J. Hytier (éd.). Variété; oeuvres. Paris, Gallimard (coll. Bibliothèque de la Pléiade, t. I), 1957b.

VALÉRY, Paul. "Au sujet d'Eurêka" (1921), in J. Hytier (éd.). Variété; oeuvres. Paris, Gallimard (coll. Bibliothèque de la Pléiade, t. I), 1957c.

VALÉRY, Paul. "Situation de Baudelaire" (1924), in J. Hytier (éd.). Variété; oeuvres. Paris, Gallimard (coll. Bibliothèque de la Pléiade, t. I), 1957d. 